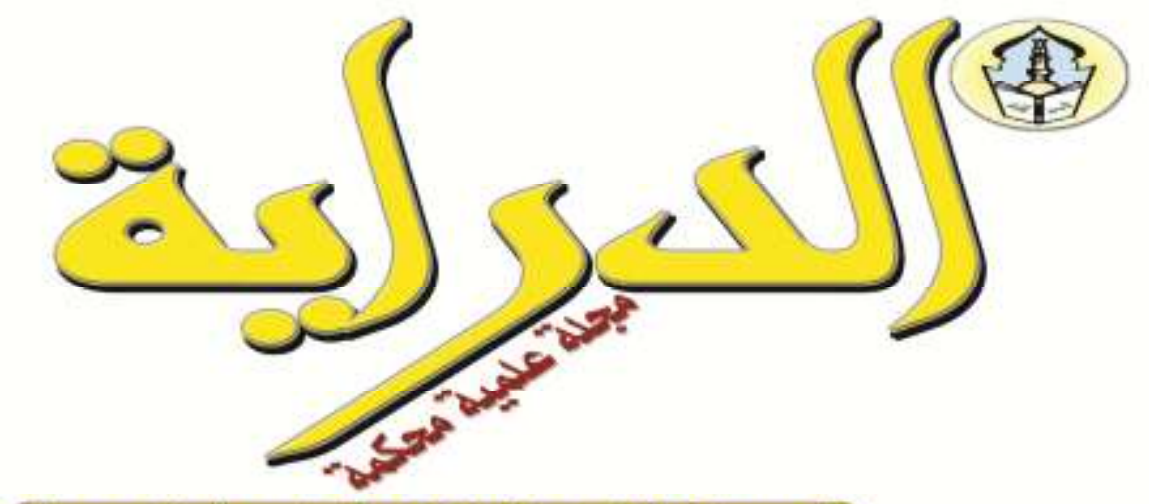

تصدرها كلية اللدراسات الإسلامية والعربية بنين بلدسوق

سلسلة من أعلام الملدرسة الطبيعية

تأمـلات فى فلسفة طاليس

أ. د ا ثروت حسين سالم

أستاذ العقيلدة والفلسفة

في كلية الدراسات الإسلامية والعربية للبنين بلسوق

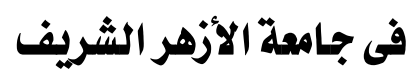




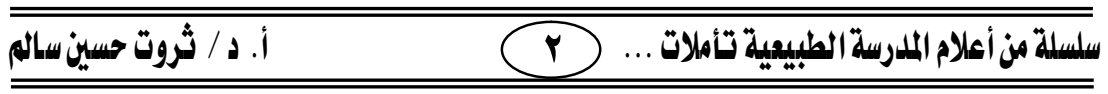




\section{مجلـة اللدرايــةة}

الحمد لله رب العالمين ، و الصلاة و السلام على أثنرف المرسلين

و على آله الكر ام ومن اهتدى بهديهم إلى يوم الدين وبعد .

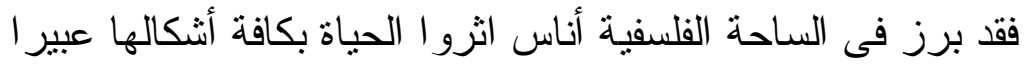

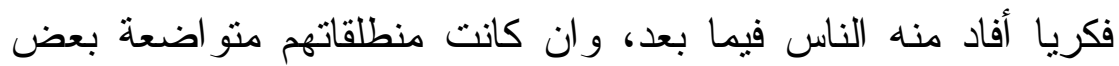
الثئ إلا أن اللاحق بنى عليها وجدد فيما قال السابق آخذا بيد البشرية

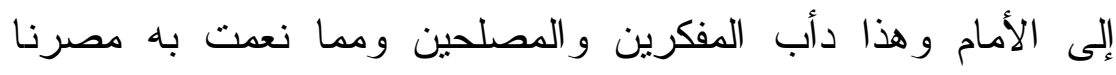

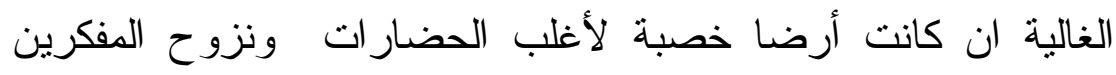
حيث وطئت أقدامهم تلاك البلاد الغالية مشمرين عن سو اعد الجد متأملين لاعلين فيما كتب أعلامها وذكروا ذلك فى كتهم وها نحن نقدم للقارى الجليل

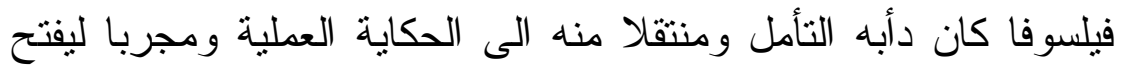

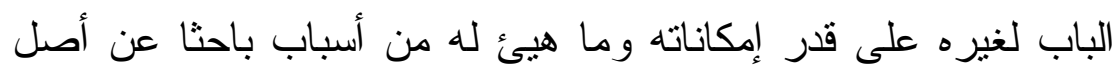

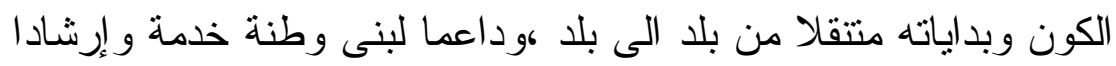

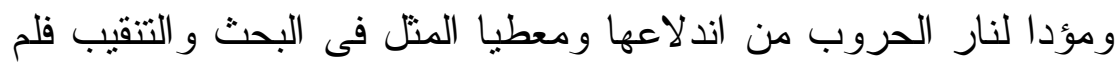

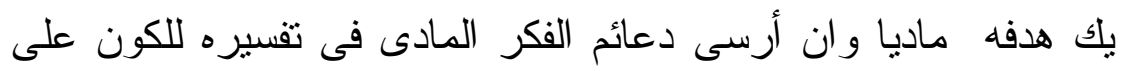
أسس طبيعية كغيره من أعلام الفلسفة اليونانية . إن حديثا عن طاليس العلم الاغريقى قر اءة لأفكاره ماله وما عليه وذلك من خلال رحلته العلمية سائلين المولى عزوجل إدر الك الركب فى التى

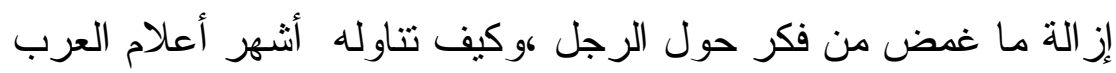
مع إرداف ذلك بدفعة إيمانية فيما يخص البحث حول نظرة الرجل.

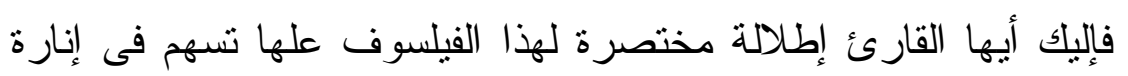

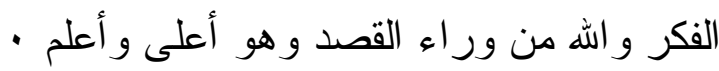




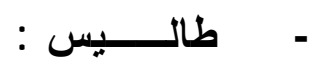

-

الزمان و المكان : - - المان

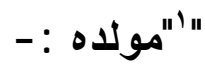

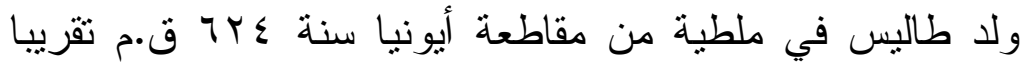

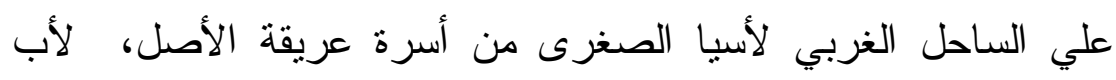

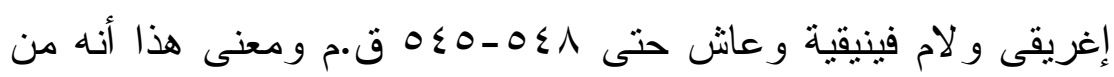

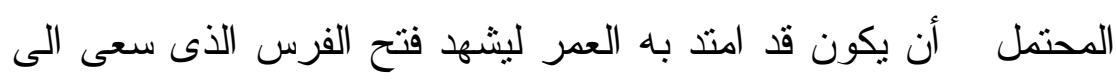

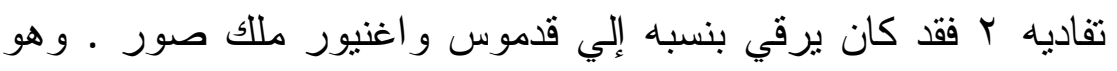

ا يرى الشهرستانى أن طلبس أول من تقلسف فى ملطية. الملل و النحل 17 الثانية 


\section{مجلـة اللدرايـةة}

أحد الحكماء السبعة (،و الذين لم تثبت قصتهم تاريخيا ولكنه انفرد بالعلم

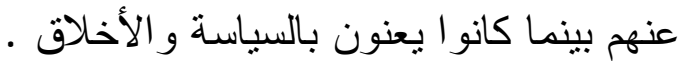

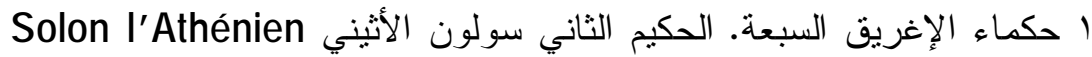

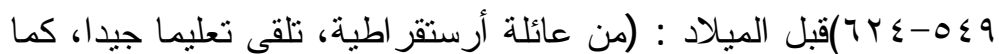

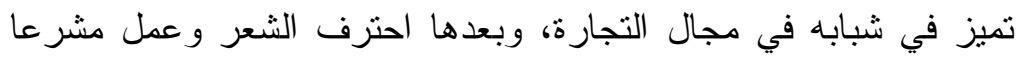

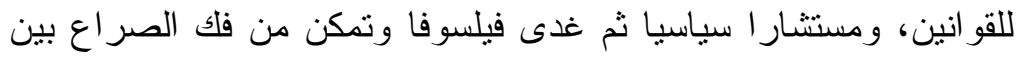
الطبقة الأرستقر اطيين و الطبقة الثعبية الني أضحى أفر ادها عبيدا بعد أن أن أنسان

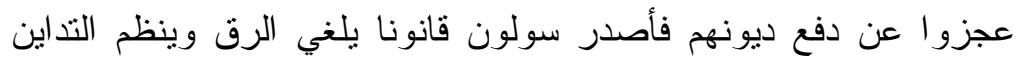
بين الناس مما أسس لانطلاقة ديمقر اطية وعدالة اجتماعية في أثنيا". ندن الندان نتعلم كل يوم أثياء جديدة" " يجب أن تتعلم كيف نطيع لتستطيع التحكم" لأنساء "لا تدعو إلى الأشياء الجميلة ولكن إلى الأمور المثالية"

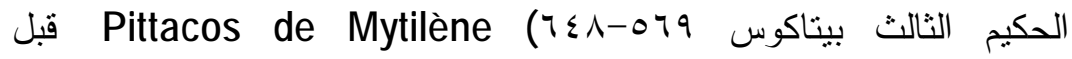
الميلاد :(.شخصية سياسية تمبزت بضبط النفس وحسن التقدير و الصدق

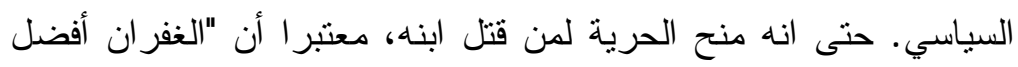

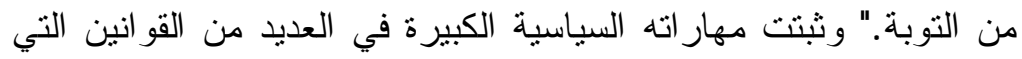

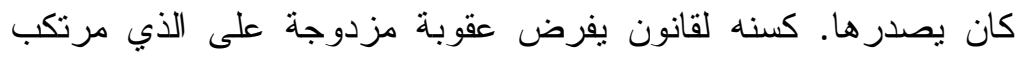

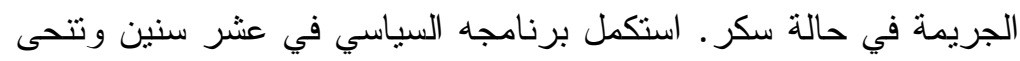

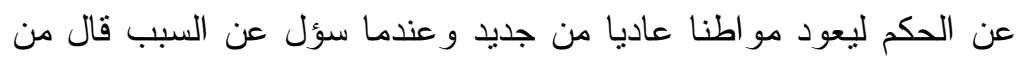

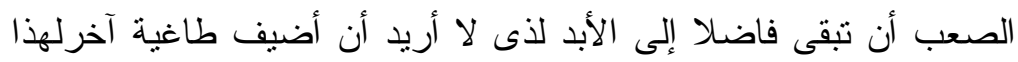

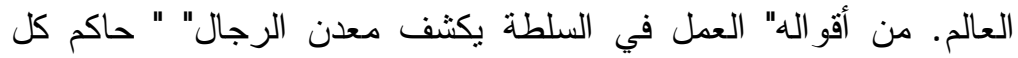

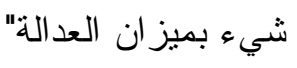

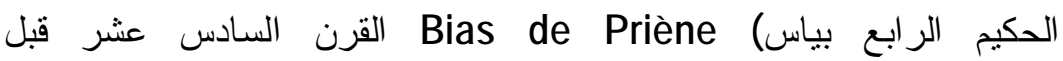

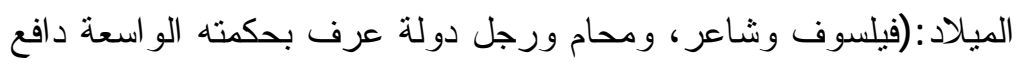
عن حقوق المستضعفين ومن طر ائف ما يحكى عنه أن ملك ليديا كان

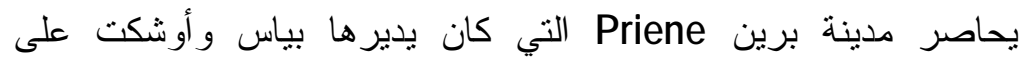
السقوط بسبب الجوع فطلب من رجاله أن يخرجو ا بغلين جيدين يحملان 


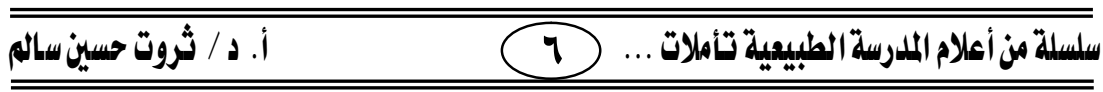

أكياسا من الحبوب من الباب الخلفي فلما وقعا في يد جنود الملك ظن هذا الأخير أن المدينة ستصمد طويلا فقرر أن يعقد صلحا مع بياس وفي لياب

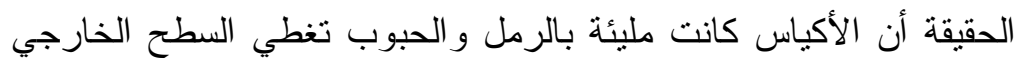

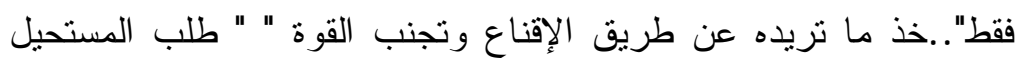

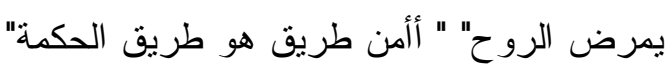

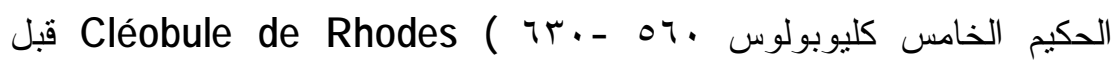
الميلاد:(سياسي يوناني قديم كما كان حاكم مستبد لمدينة ليندوس. تميز بوسامته الفائقة وقوته الرهيبة وجاء في الأساطير أنه ينحدر من أسرة

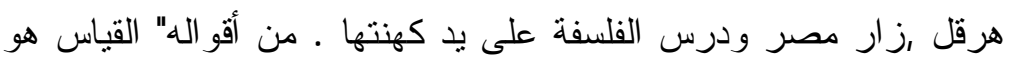

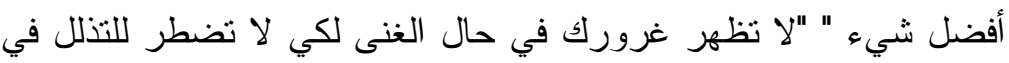

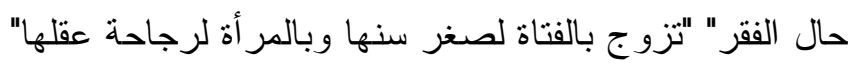
الحكيم الساد نشيلو الإسبرطي) Chinon de Sparte عاش في فئس القرن

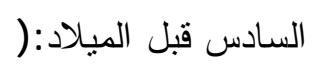

كان فيلسوفا ومشرعا عرف بعبارته الثهيرة "اعرف نفسك بنفسك" الني وجدت

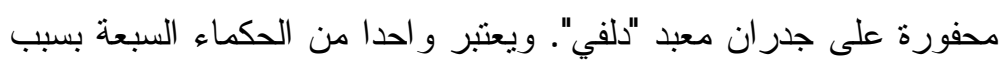

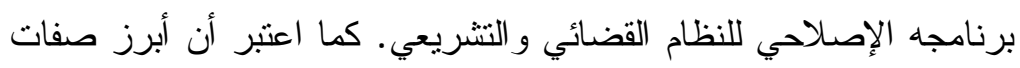

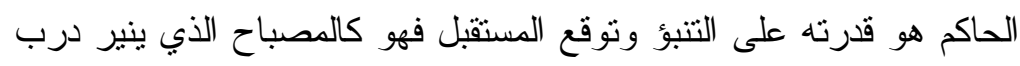

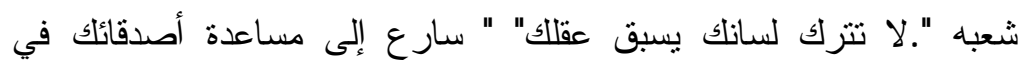

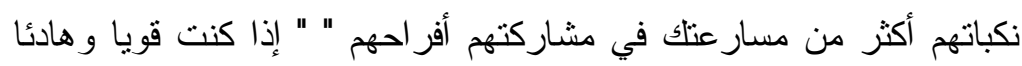

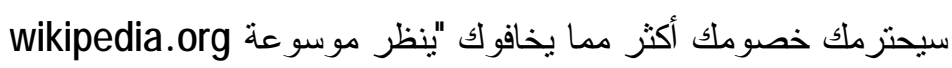

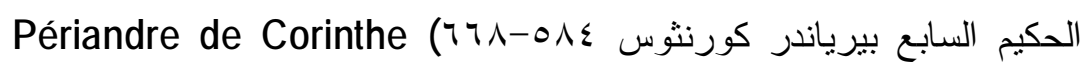

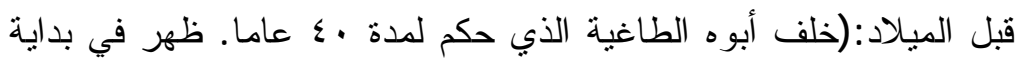

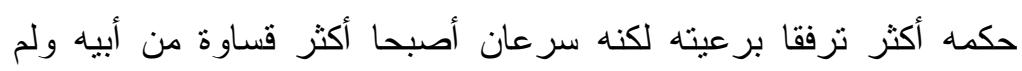

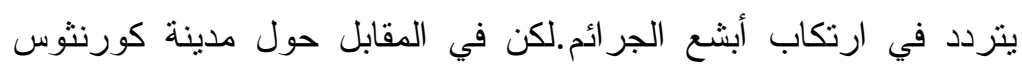

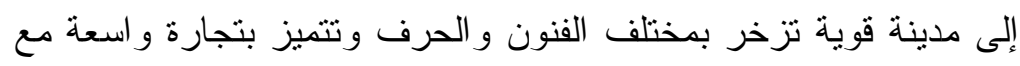
بلدان ومدن الجوار كما قام بحضر الرق وسن قون انين تحضر التجول 


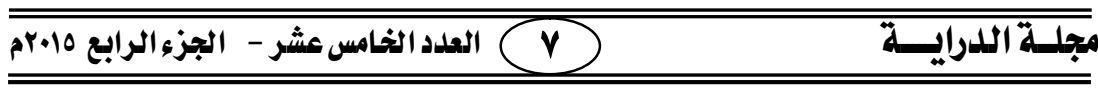

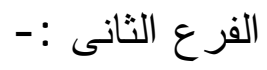

ثقافته : -

طوف طاليس بكثثر من البلاد بحثا عن المعرفة وطرقها فكثف علي دراسة العلوم المختلفة .فبلغ مصر و أخذ عن الكهنة المصريين بعضًاً من المعرف الرياضية،بذلك توصل لطريقة رياضية لقياس ارتفاع الهرم بناء علي قياس ظله ومقارنته بظل العصا و عمل كمهندس بحري حتى فاق أرباب البحرية وذلك بوضع تقويم بحري للملاحين ضمنه إرشادات وقو اعد فلكية كانت لها قيمتها الكبرى في تاريخ الملاحة . كذللك تتبأ بكسوف الثمس ميه م وبذلك حسم اللقاء العسكري بين الليديين و الميديين،ووقتنئ بدأ نجمة يسطع في سماء ملطية ، ودعي بالحكيم وارتبط اسمه بالحكماء السابقين عليه ، وبدأ من خلال رحلاته العلمية إخخال علوم أخرى إلي موطنة، ومنها علم الهندسة مما عاينه وشاهده من علم المصريين بالهندسة ،كما قدم تفسير ات لظاهرة فيضان النيل وتكوين الدلتا ،وقد أثتبت جدارته و أحقيته بنسبة الحكمة إليه وذلك في وجه المعارضين، حيث استأجر كل معاصر الزيتون لعلمه سلفا (النها

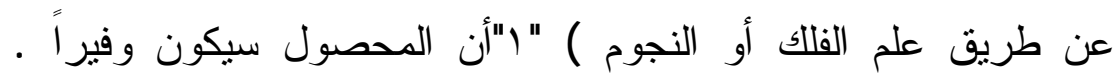

ليلا ـمن أقو الد" لا تتصرف على أساس المصلحة المادية" " حافظ على المى

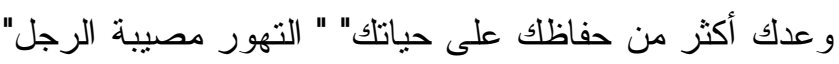

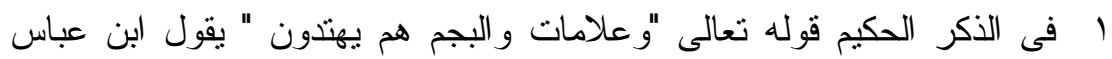

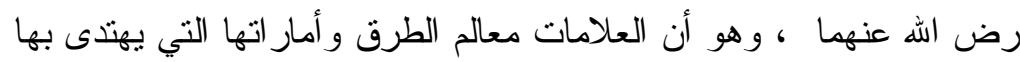

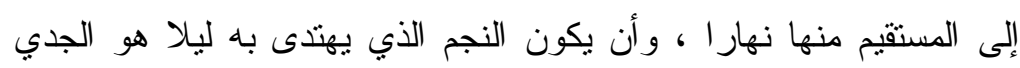

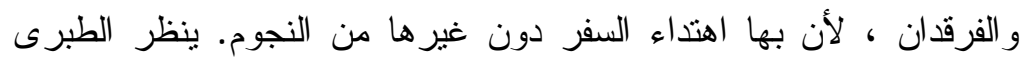

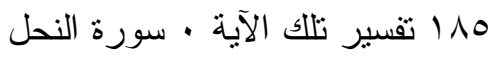


أ. د / ثروت حسين سائه

(1) سلسلة من أعلام المدرسة الطبيعية تأملاتة ...

وكان الوقت شتاء - حتى إذا جاء المحصول كذللك وأر اد كل واحد أن يعصر زيته اضطروا جميعاً للذهاب إليه ،ومن هنا أثنبت أنه بحنكته

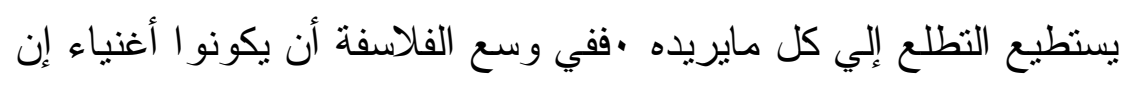

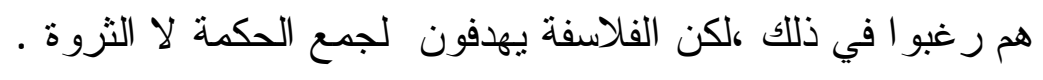

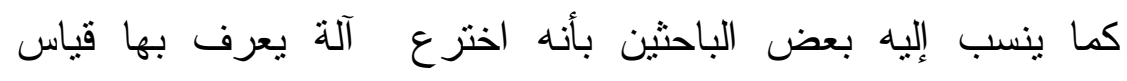

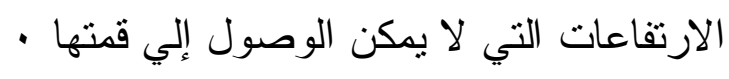

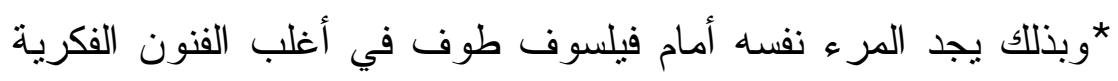
ومن هنا كان رائدا من رواد الحكمة بوبعد هذا العرض الموجز لهئ لحياة

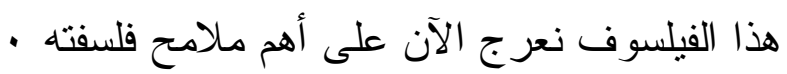




\section{مجلـة الدرايــةهة \\ الفرع الثالث}

\section{فلسفته}

أولاً : تعدد الآلهة

اعتمدت النظريات السابقة علي الأساطير في تقسيرها لوجود الإله وتعدده ، فقد كانت تلك البقعة(اليونانية ) تؤمن بتعدد الآلهة،

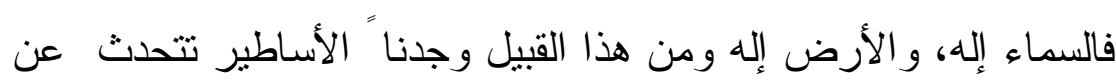
تزاوج السماء بالأرض وعنهما صدرت الآلهة الأخرى ابتداء بكرونوس ولاء وصن و انتهاء بزوس رب الأرباب وحاكم السماء و الأرض •فى زعمهم - مبدأ

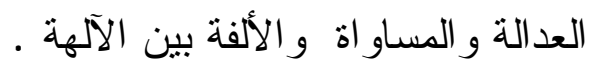
ومن هنا فقد حلت النظرة الطبيعية البحتة محل هذه النظريات ولم يسلم طاليس من خبر ها فقد آمن يؤمن بتعدد الألهة لا الله وذلك دين أهل اليونان و الإله لله صفة الكمال عن البشر · و أثز عنه قوله : "أن كل هل الأشياء مليئة بالألهة أو بالنفوس" -( (1) وهذا القول ينبغي أن يفسر في لهن إطار تفسير المادة بالحياة ولهذا وصف مذهبه بالحيوية وهي نزعة

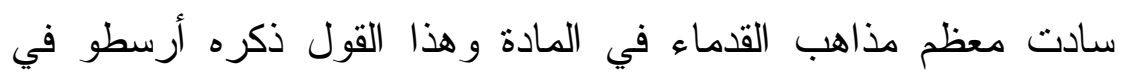

ا برى نيتشه أن طالبس فال بحقائق ثلاث "من وجهة نظره" انه تحدث عن أصل

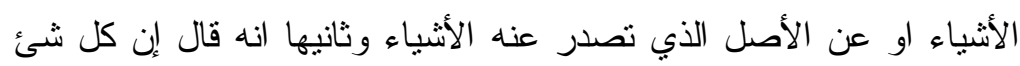

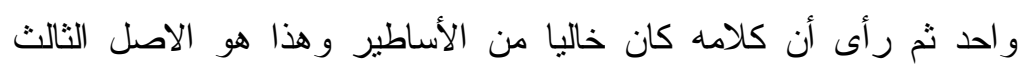

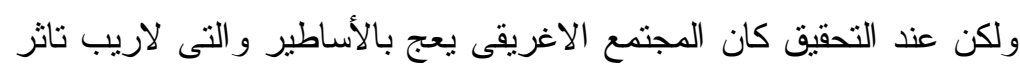

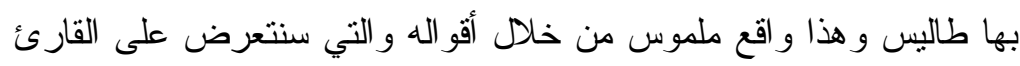

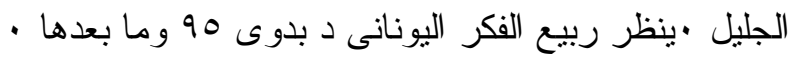




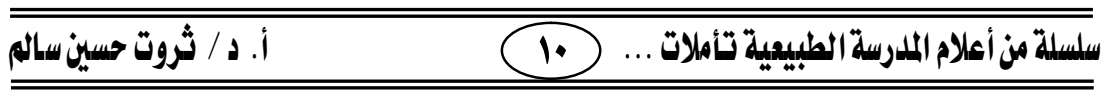

كتاب النفس(1) معلا أن طاليس ربما كان يعني بذلك أن النفس منتسرة في جميع أرجاء الكون ،وأن جميع الأشياء تتصف بالحياة •او بعبارة أخرى تلك النفس الكامنة فى الأشياء و المحركة لها و التى هى فى لى لـ الأصل كامنة فى الماء وتحركه وتحدث تغير اته وتحولاته المختلفة ،ومن ذلك فكل شئ حى وكل شئ فيه نفس : ومن ثم فإن طاليس فى نظر البعض أنزل الآلهة من سمائها وجعلها تسكن جميع الأشياء ،كما أنزل الثعر اء الآلهة واسكنو ها جبل الأوليمب .ومما نقله البعض فى هذا الإطار تضارب الرجل فى أقو اله حيث يعلل قوله: - " إن فى الكائنات الحية وغير الحية قوى غامضة حية تحركها فيركن الى القول بان كل شئ مملوء بالآلهة ومرة أخرى ينزع إلى القول بأن للمغناطيس نفسا

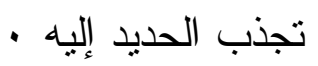

ومما سبق يعلم القارئ نظرة طاليس للإله كانت مضطربة لاتقى بمعرفة نهائية ولكن يحمد له تطلعه إلى ما ور اء الأشياء بحثا عمن يحركها وهو بهذا امتداد معرفى للعقل الانسانى فى محاولة للإجابة عن تساؤلات النفس البشرية حول هذا الإله ماله

ا ينظر فجر الفلسفة اليونانية /د احمد الأهو انى اOه ومن نافلة القول انه قد نسب

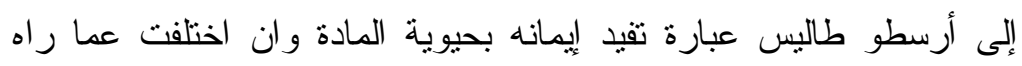

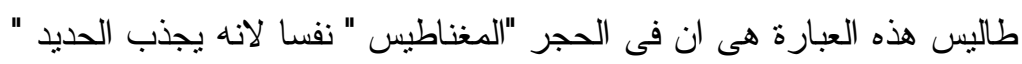

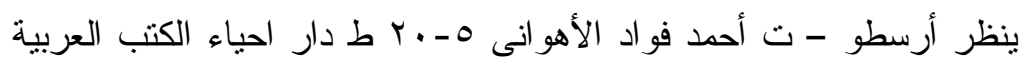




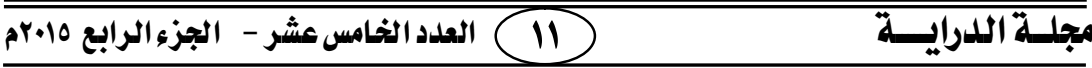

\section{ثنانبا: -أصل الكون : -}

كان لنشأة طاليس علي شاطئ البحر ومشاهدته لتصاعد

الأبخرة و أفاعيل الضباب ولمعان البرق أثره الواضح في قوله (إن

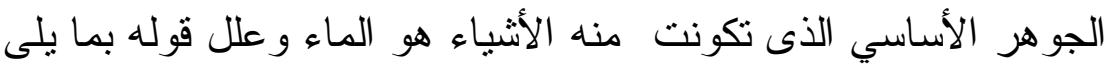

أو لا: - - الماء قو ام كل شئ "r* فالكائنات تعتمد عليه فهو يري أن النبات و الحيوان يتغذي بالرطوبة و لا بسنطيع الحياة بدونها و الرطوبة

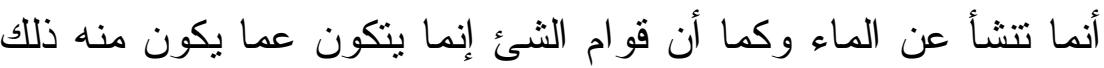

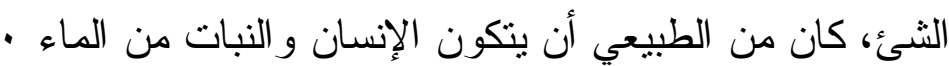
ثانيا: -عملية النولد نفسها - فالحيوان و النبات في نظرة يولدان من النان الجر اثثم الحية و هذه الأثباء رطبة و الرطوبة من الماء ـ فالمادة الحية مشتملة على روح الحياة فكل جزء من أجزاء الصنعة فيه حياة أو فيه الآلهة واظهر ما يتضح من أجزاء المادة هو المغناطيس عندما يشاهده

ا تميز طالي عما سبقه من الثعراء واللاهوتيين بإسناده الأمر إلى الدليل بينما

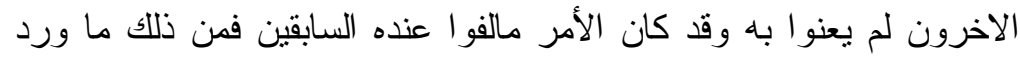

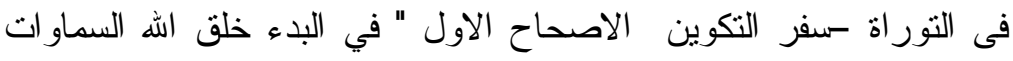

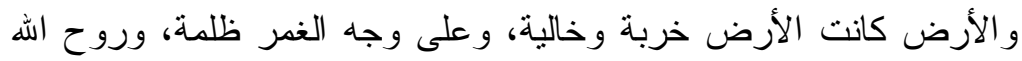

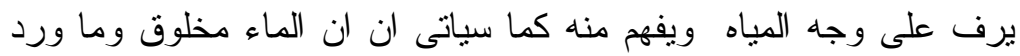
فى قصة مصرية فى البدء كان المحيط المظلم او الماء الاول حيث كان كان الفاء اتون وحده الإله الأول صانع الآلهة والثشر " ينظر تاريخ الفلسفة اليونانية -

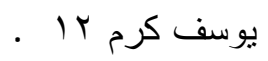

r بعتبر طاليس بنزعته المادية برده الأثياء إلى الماء من القائلين بالمادة الحية

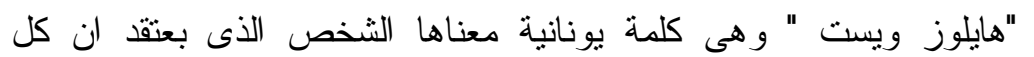
الأثنياء حية" ينظر أعلام الفلسفة 97 


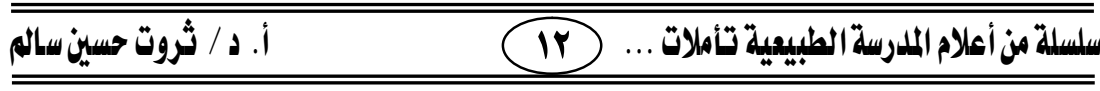

يجذب الحديد .فالتزراب مثلا ليس إلا ماء تبخر و السحاب ليس إلا

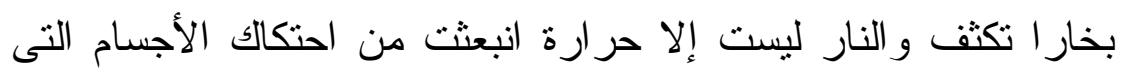

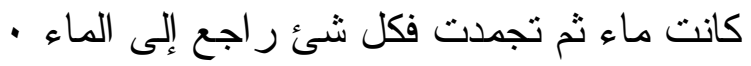
ثالثا: - أن الثر اب يتكون من الماء ويتحول إليه وهذا الأخير شيئا فثيئا

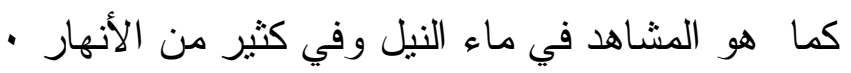

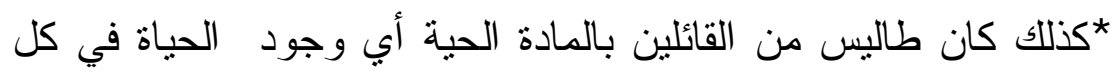

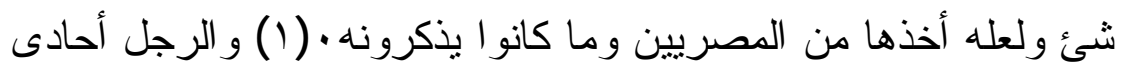
النظرة المادية من الذين "يقصرون نظرتهم على المادة وحدها ويققون

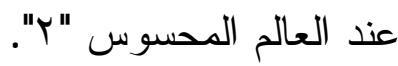

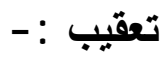

بري بعض الباحثين أن كلام طاليس حول الماء وكونه أصلا للأشياء

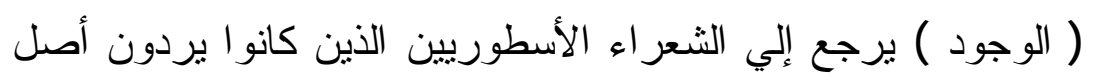

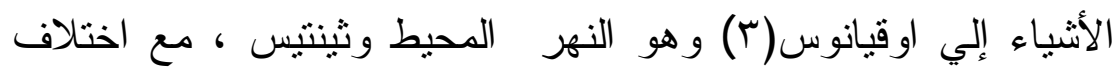

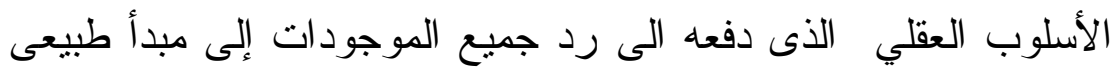

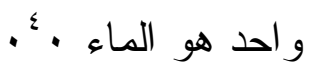

1 ينظر الفلسفة اليونانية أصولها وتطوراتها 9 \&و المعجم العلمى لمتتقدات الثعوب

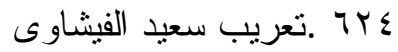

r ج أضواء على الفلسفة اليونانية د حموده الجمل

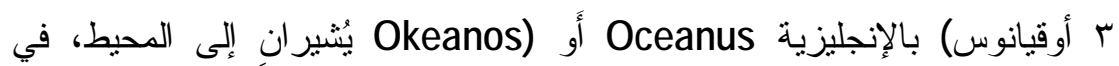

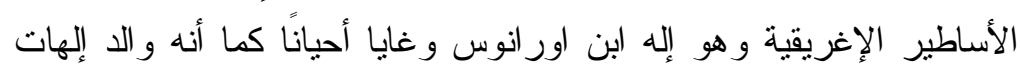

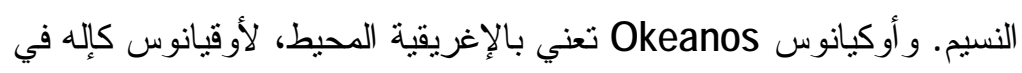
الميثولوجيا الإغريقية الكثير من الحكايات و القصص المختلفة. 


\section{مجلـة اللدرايــة}

* وهو في نظر البعض (كلامه حول أصل الوجود )مجرد خرافات

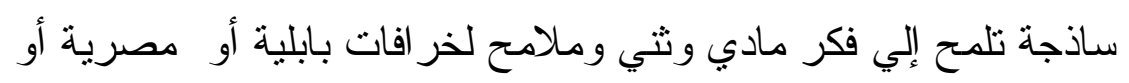
أنثورية قديمة . *بينما بعد أرسطو هذه المحاولة ( أو الفكرة ) راجعة إلي ملاحظات

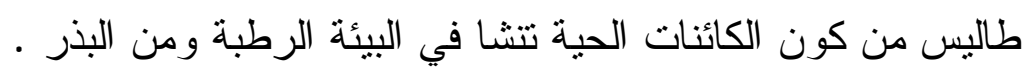

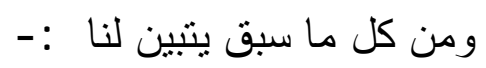
*إن طاليس كان موسوعة علمية بحسب زمنه و آليات ما اعتمد عليه -

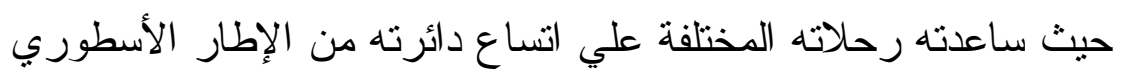

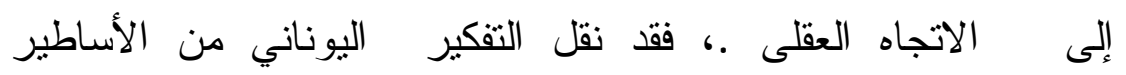

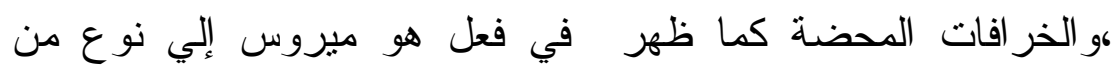

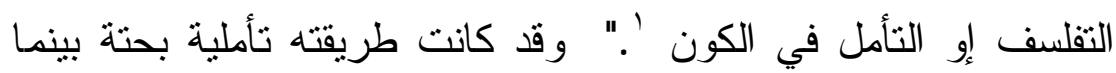
كانت عند المحدثين تجريبية . فقد جعلو امن الهيدروجين العنصر المولد للماءوهو العنصر الكيميائي

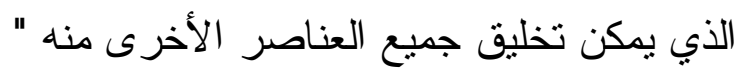
كذلك يلحظ القارئ لفلسفة الرجل أسهامه فى البحث العلمى فى الرؤية

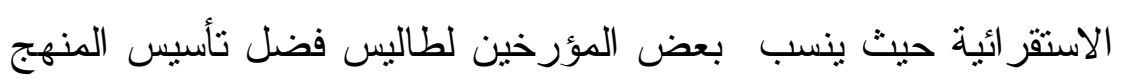
العلمي القائم على تفسير الظواهر الطبيعية وفق الأسباب الماورائية و الجغر افية، ويطلقون عليه الفيلسوف الطبيعي الأول.

ا ينظر قصة النزاع بين الدين و الفلسفة ـ د توفيق الطويل 7 و ما بعدها 


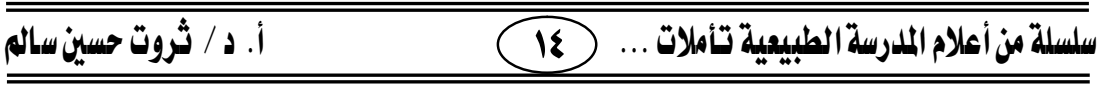

ويمكن للقارئ أن يلحظ أن طاليس أول فيلسوف عرفته الإنساتية من

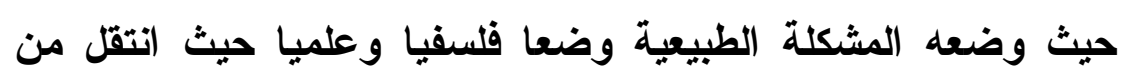
الميثولوجيا(1 )واللاهوت الى العلم والتجربة متوصلا الى احكامه الكلية عن كطريق التجرية) فقد صبغ الفلسفة فيما قبل سقراط بتلك الصبغة المادية التى عرفت بها

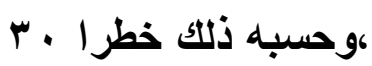

*2*أما في مجال الرياضيات، فقد أخذت منحى جديدا بعد أن

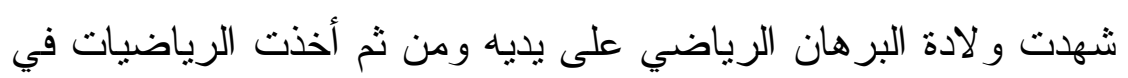
الابتعاد عن كونها وسيلة قياس لتخطو أولى خطو اتها في عالم البه البحث الرياضي، و التي تقوم على مبدأ البرهنة.

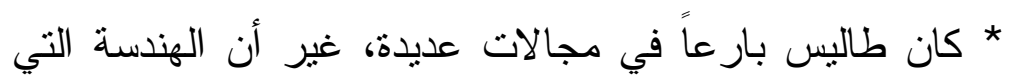

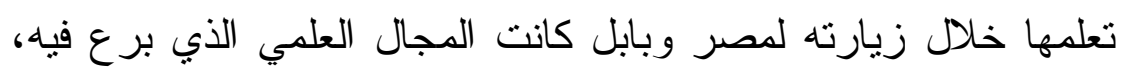

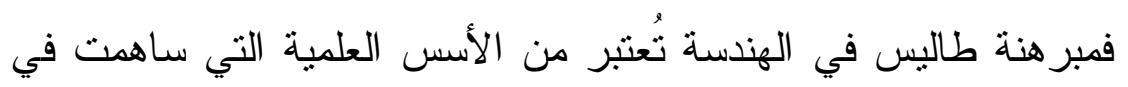

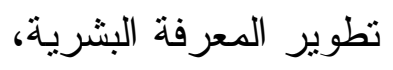

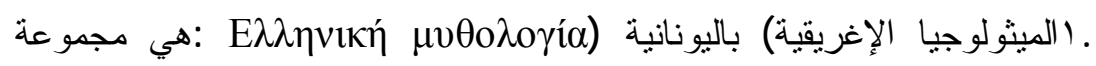

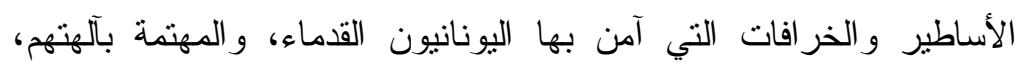

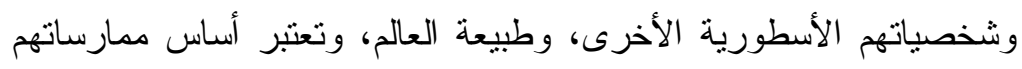

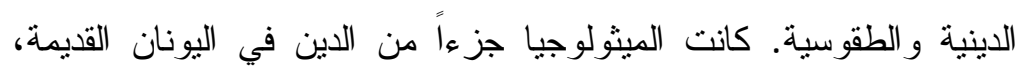

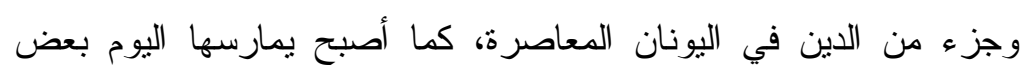

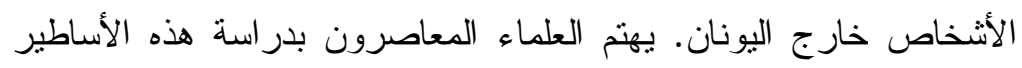
لفهم الحياة الدينية والسياسية في اليونان القديمة إضافة إلى معرفة نشأة هذه الئان

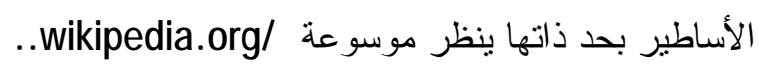

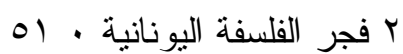
r قصة الفلسفة اليونانية د زكى نجيب - احمد امين 10 ط لجنة الناليف و النثر 


\section{مجلـة اللرايــة}

و الرجل وان أفاد بالفكر المصرى لكنه فى نظر بعض الباحثن

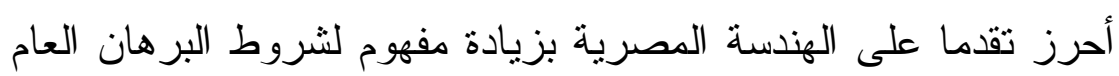

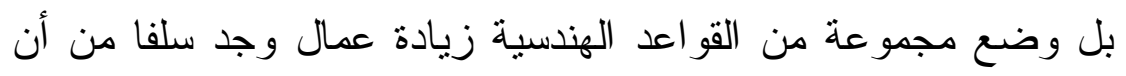
قطر الدائرة يقسمها إلى قسمين متساويين بل زاد بأن زوايا الدثلث

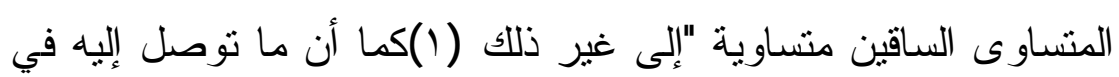

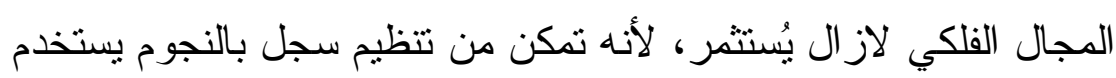

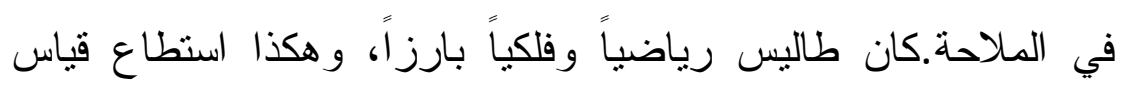

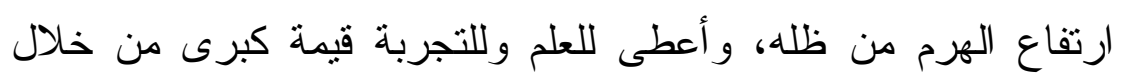

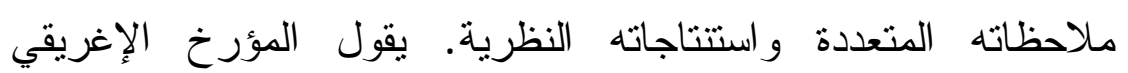

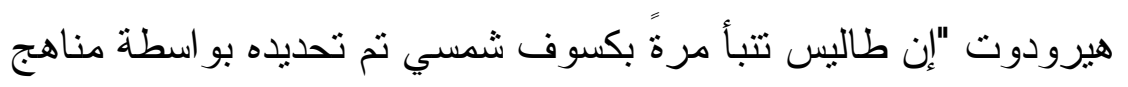

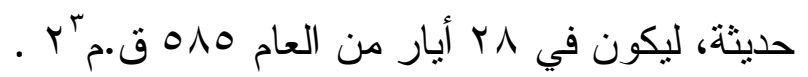

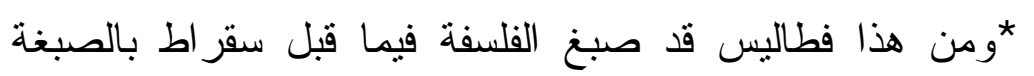

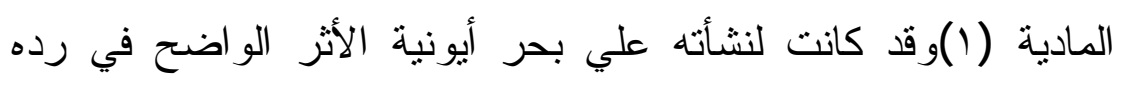

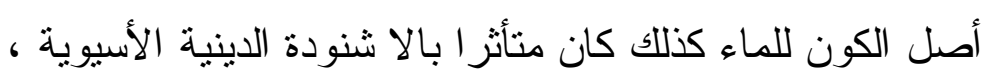

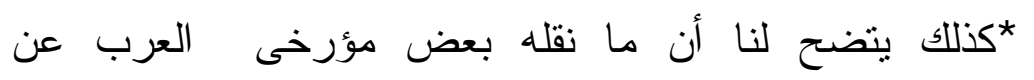
طاليس(*) في الإله ليس له مرد من الصحة لأنه كان فيلسوفا ماديا للم

ا تاريخ العلم جورج سارنون // بآب .

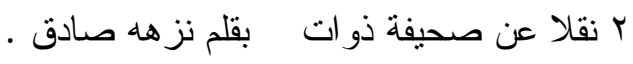

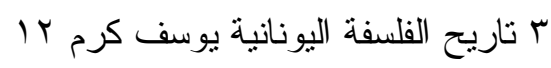

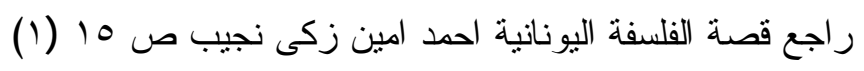

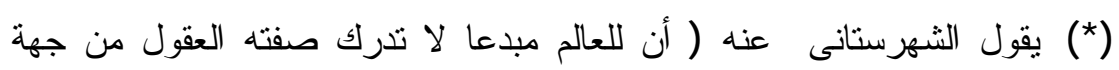

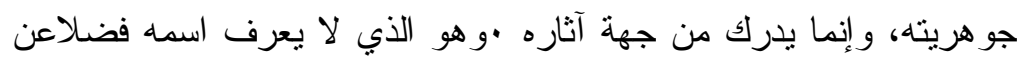

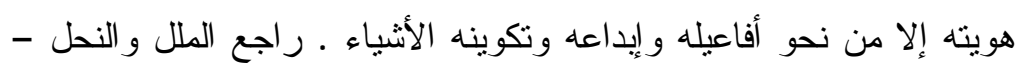

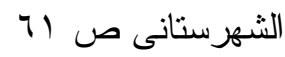




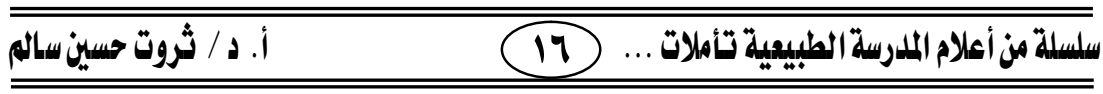

يتعد بحثه دائرة الطبيعة ولم يتتاول الإله و لا البحث في هويته، ولا في

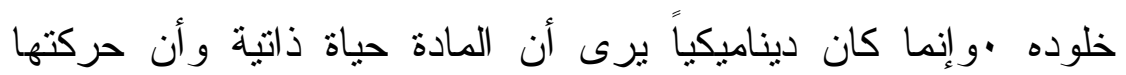

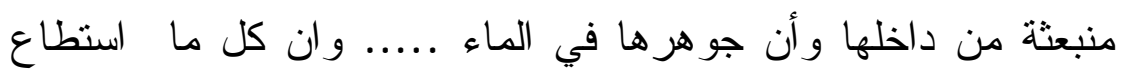

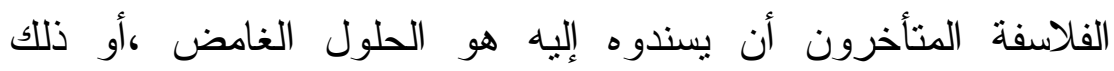

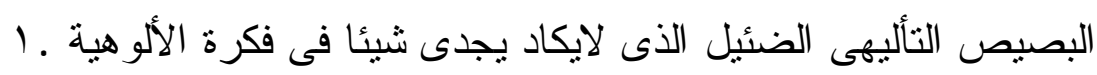

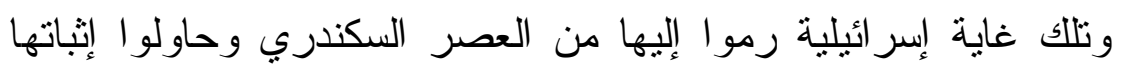

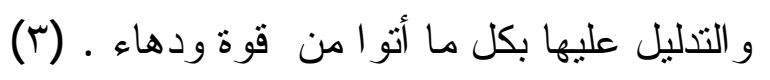

وبعد هذا العرض يمكن للباحث الوقوف على محاور منها : -

أو لا: - **تعد فلسفة طاليس شيئا جديدا حيث نظر إلى تتوع الكائنات بعيدا عما سبقه ينتوع القوى الطبيعية والرواية عن الآلهة يل فلئل

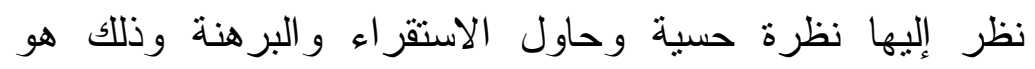

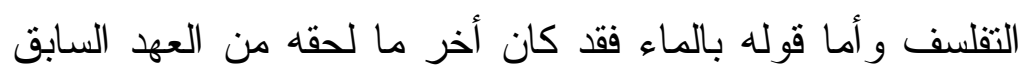

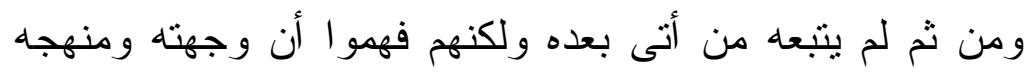

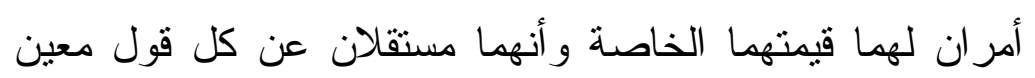

ا ينظر الفلسفة اليونانية أصولها وتطور اتها 9؟

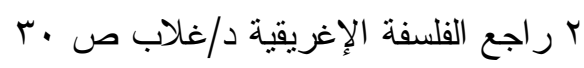

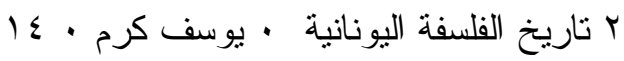




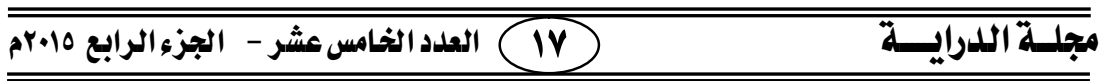

ثانيا : - إن الرجل بعد رحلته بالمادة الحية وذاتيتها و القول بأزليتها

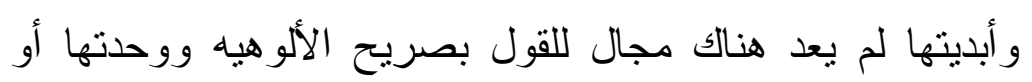

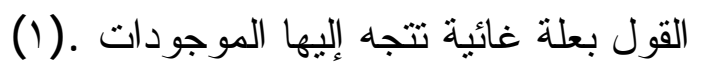

ثالثا: - تأثزر بالفينتقيين فيما رآه بالنسبة لعلم الفلك فقد اخذ عنه تحسين

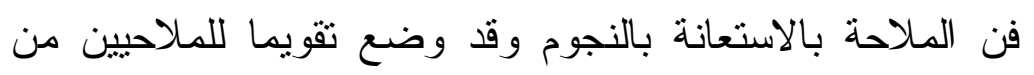

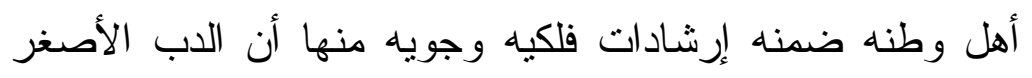

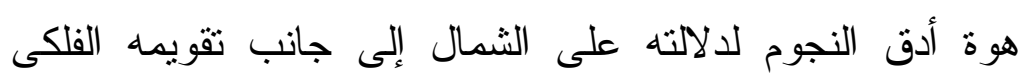
المسمى بار اديجما ويعد من أقدم ما عرف وفيه يبين أوجه القمر لألئه

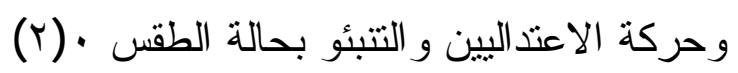

رابعا: - اعتر افه بالتلمذة على يد المصريين القدماء فى مجال المساحة

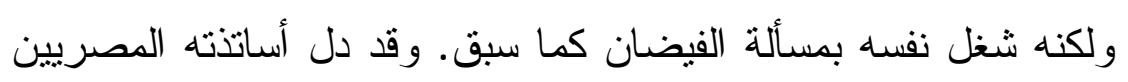

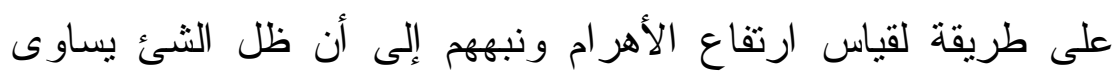

1 عقد د الجمل مقارنة بين ماورد ذكره فى اى الذكر الحكيم عن الماء وقوامه

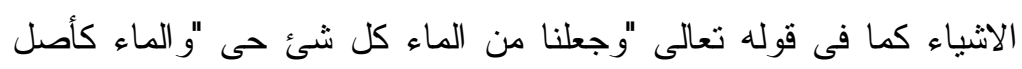

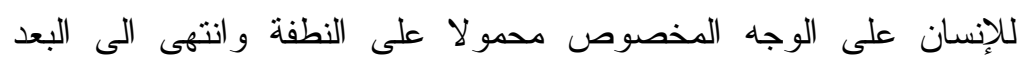

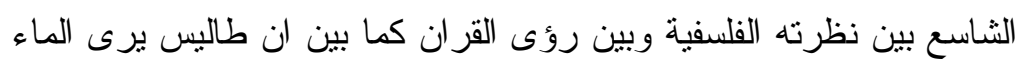

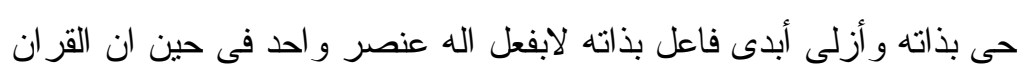

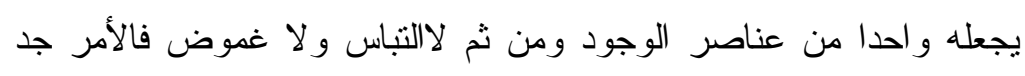

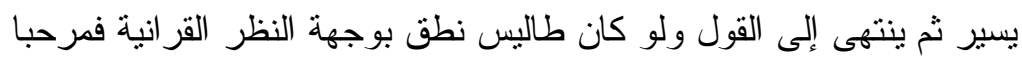

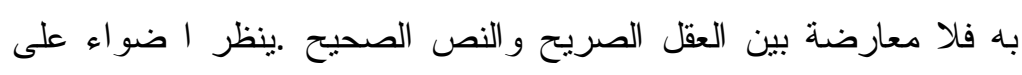

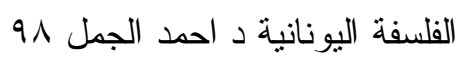

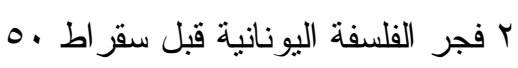




\section{سلسلة من أعلام الملدرسة الطبيعية تأهلاتة ... TIN}

ارتفاعه فى وقت من النهار فطول الأهر ام فى ذلك الوقت هو مقدار

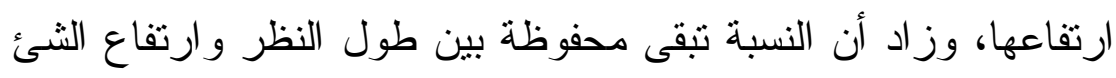

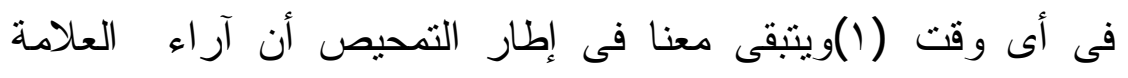
الثهرستانى فى هذا الإطار من وصفه لطاليس بتلك الصفات الرائعة

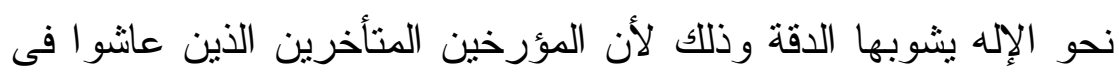
القرن الخامس و السادس الميلاديين مثل ثيودر وسرجيس ....... . . لمن الذين نقلو ا الفلسفة اليونانية إلى السريانية ومنها إلى العربية فيما بعد فى ولى عصر الترجمة لم يبحث احد منهم عن الموازنة بين النصوص العربية

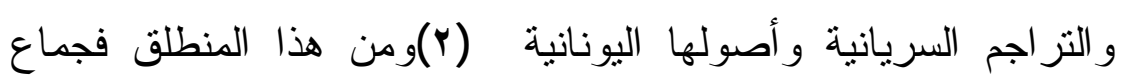
آر اء الرجل لاتتهض لما ذهب إليه العلامة الثهرستانى(r) فى اعتبار

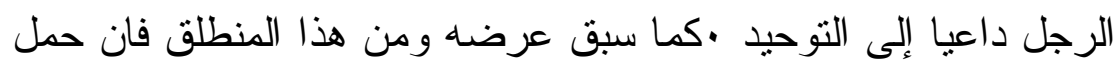

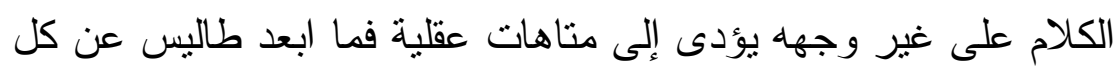

ا ينظر الفلسفة اليونانية مدارسها وأعلامها · د محمد فتحى عببد اله - د جهيان

$$
\begin{aligned}
& \text { الثريف r. }
\end{aligned}
$$

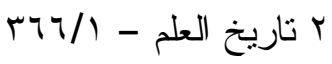

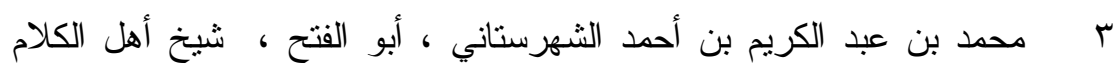

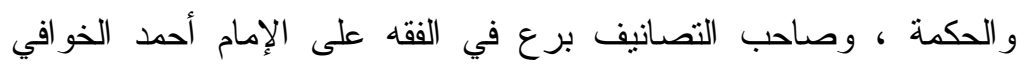

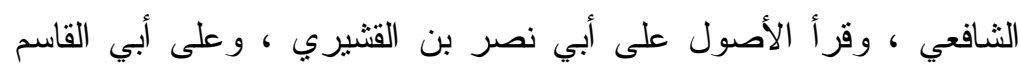

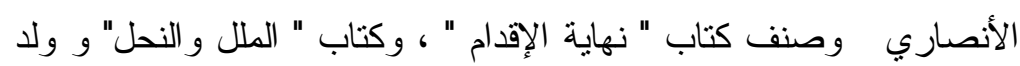

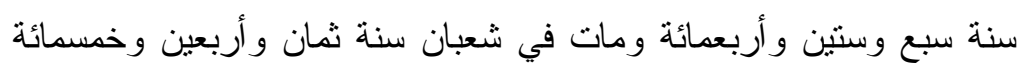

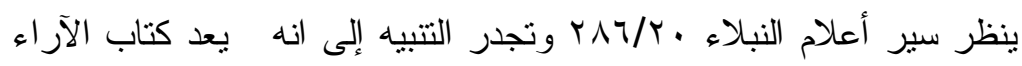

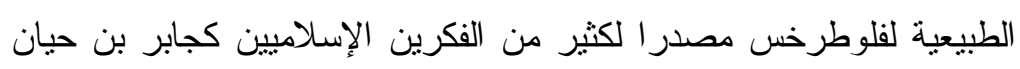
و الثهرستانى و المقسى و الثهرزورى حيث قدم لطاليس وكان منه الاقتباس الطيان

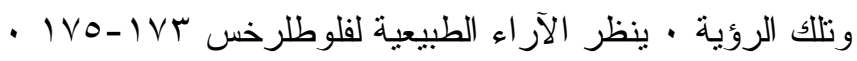




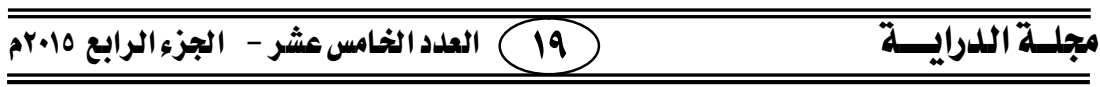

هذا عن فكرة التوراة القائلة "أن الإله قد خلق كل شئ من الماء

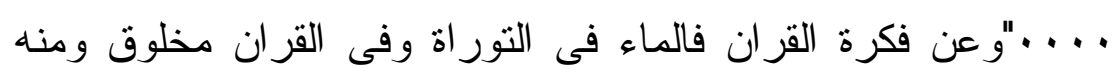

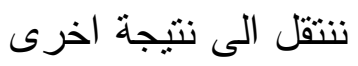

خامسا : - عملية العزو و التدقيق العلمى خاصة الترجمات جانبت بعض مؤرخي العرب فقد "كفوا أنفسهم مؤونة كون طاليس موحدا وسارو الفئ ور اء من يقول بذلك و عزوا إليه عبار ات تدل على انه كان مؤمنا بالإله إيمانا تقديسيا لايقل عن إيمان الخاصة من المسلمين ليثبتو ابها انه

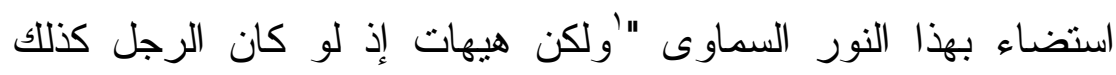

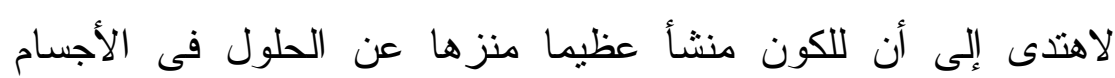
ونسب إليه خلق الماء وغيره من جزئيات الكون كما هو فى تعاليم

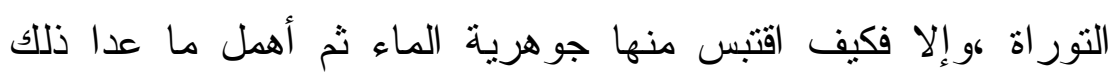
إهمالا تاما .

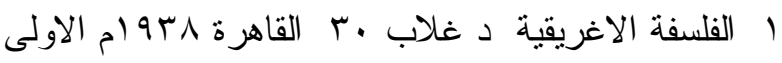

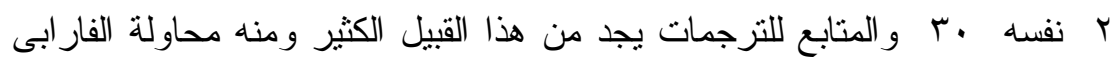

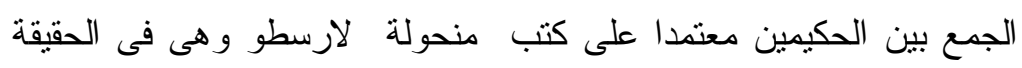
من تاسوعات افلوطين وهذا معروف لارباب البحث العلىى. لإنى 


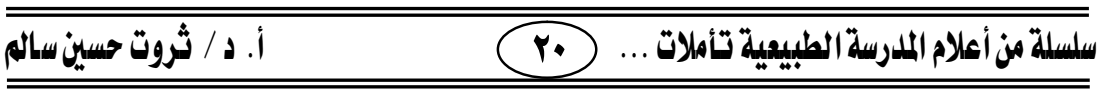

سادسا : - أن طاليس لم يتكلم عن عنصر أول اعلي هو منبع الصور

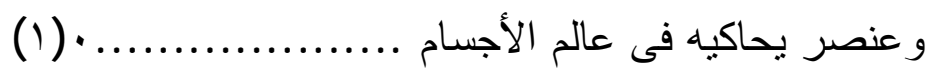
سابعا : - إن الطبيعيين الأوائل لم يصلو الإلى فكرة الإله بكل صورها

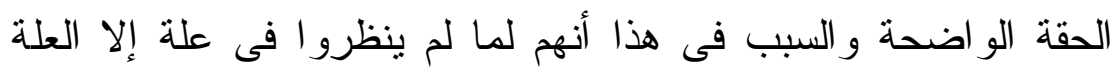

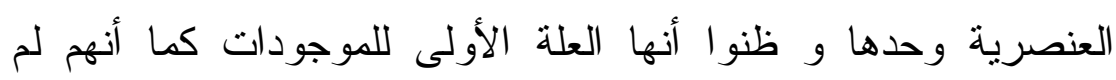

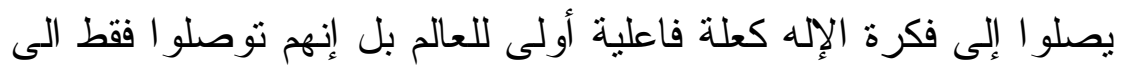
معرفة علة عنصرية إلى عنصر و احد كعلة أولى للموجودات (r)

وبعد فكانت هذه إطلالة موجزة عن هذا العلم اليوناني ومدى إسهامه

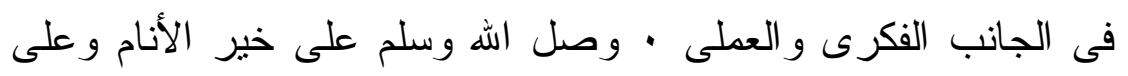

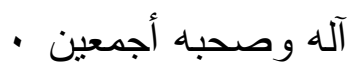

1 نشاة الفكر الفلسفى النشار 117 ط دار المعارف · وينظر الفلسفة اليونانية

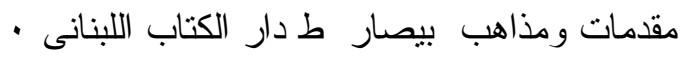

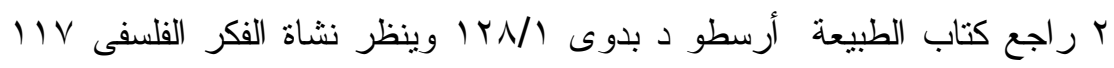

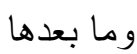

